\title{
Research on Scientific Management of Pharmaceutical Laboratory based on Demand and Supply Chain Management
}

\author{
Lijuan Cheng \\ Yichun Vocational Technology College, Yichun 336000, China \\ 20175490@qq.com
}

\begin{abstract}
Pharmaceutical care means that pharmaceutical professionals use pharmaceutical professional knowledge and tools to provide various services related to drug use to the public (including medical nurses, patients and their families, and other groups concerned about drug use, etc.). With the transformation of higher medical education from elite to mass training, and the policy adjustment of the domestic pharmaceutical industry, the employment situation of pharmaceutical graduates has become increasingly severe, which has become one of the key concerns of medical colleges and universities. The opening of the laboratory has brought a series of problems, such as the increase of mobile personnel, experimental projects, new hazard sources and uncertain factors, which has brought many troubles and challenges to the safety management of the laboratory. Combined with the theory of supply chain management, this paper puts forward strategies and measures to strengthen and improve laboratory safety management, to provide reference for realizing scientific and fine management of laboratory safety management and ensuring the safe and orderly operation of laboratory.
\end{abstract}

Keywords: Demand and Supply Chain Management; Pharmaceutical Laboratory; Scientific Management.

\section{Introduction}

With the rapid development of China's market economy, especially in the field of e-commerce, the logistics industry has entered a period of vigorous development. Some world-renowned logistics enterprises, such as FedEx, UPS, DHL, etc., have continuously invested in the construction of logistics facilities and actively explored the domestic market to seek joint business with domestic enterprises [2]. Pharmaceutical care means that pharmaceutical professionals use pharmaceutical professional knowledge and tools to provide various services related to drug use to the public (including medical nurses, patients and their families, and other groups concerned about drug use, etc.) [3]. According to the training objectives of pharmacy major, most of the major courses of pharmacy major contain experimental teaching links [4]. The transformation of higher medical education from elite to popular training, coupled with the policy adjustment of the domestic pharmaceutical industry, the employment situation of pharmaceutical college graduates has become more and more severe, which has become one of the key issues of medical colleges and universities [5]. The opening of the laboratory has brought a series of problems, such as the increase of mobile personnel, experimental projects, new hazard sources and uncertain factors, which have brought many troubles and challenges to the safety management of the laboratory [6].

With the increasing degree of global integration, individual logistics enterprises can't cope with market changes quickly and accurately, and the competition among enterprises is no longer limited to the competition among traditional enterprises, and the competition among supply chains becomes more and more prominent [7]. The laboratory becomes an important place for experimental teaching, training students' skills and developing students' intelligence. Therefore, we must attach great importance to the management and construction of laboratories, and practically create conditions, strengthen the management of laboratories, do a good job in laboratory construction, and improve the efficiency of laboratories [8]. In order to adapt to the development of the whole industry and meet the needs of various types of logistics talents, many universities in China have added logistics management, logistics engineering or supply chain and other related majors [9]. Pharmaceutical college students are mostly engaged in pharmaceutical sales, pharmaceutical basic production, quality 
inspection and quality control, and relatively few are engaged in higher-level work such as pharmaceutical management, drug innovative R \&amp; D and original drug development. Because there are many toxic, harmful, flammable and explosive reagents in the laboratory, fire prevention, anti-theft and waterproof cannot be ignored, the laboratory has a large workload and many things [10]. Therefore, strengthening the construction and management of laboratories, rationally and scientifically managing pharmaceutical laboratories, and making them serve the teaching better, are also important components of school teaching work. How to strengthen and improve the safety management of laboratories, realize the scientific and refined management of laboratory safety and ensure the safe and orderly operation of laboratories is a problem that universities and their related functional departments and laboratory managers should seriously consider and try to solve.

\section{Construction Goal of Supply Chain Management Laboratory in Colleges and Universities}

\subsection{Cultivate and Improve Students' Practical Ability}

Under normal circumstances, students' learning is mainly based on their brains, including cognition, judgment, analysis, memory, etc. Their practical operation ability is relatively weak, and this ability is precisely the most basic survival ability that students should have after entering the society. Most pharmaceutical college students are engaged in pharmaceutical sales, basic pharmaceutical production, quality inspection and quality control, while relatively few are engaged in higher-level work such as pharmaceutical affairs management, innovative drug research and development, and original drug development. By organizing students to participate in various experiments such as application software and hardware installation, equipment operation and supply chain monitoring, the laboratory fully exercises and cultivates students' practical operation ability. The supply-demand relationship of higher education is like that of manufacturing enterprises, so the supply chain of higher education naturally exists. Compared with the relevant nodes and processes of general enterprise supply chain, the macro form of higher education supply chain is also similar to it, but the specific contents are different, as shown in Figure 1.

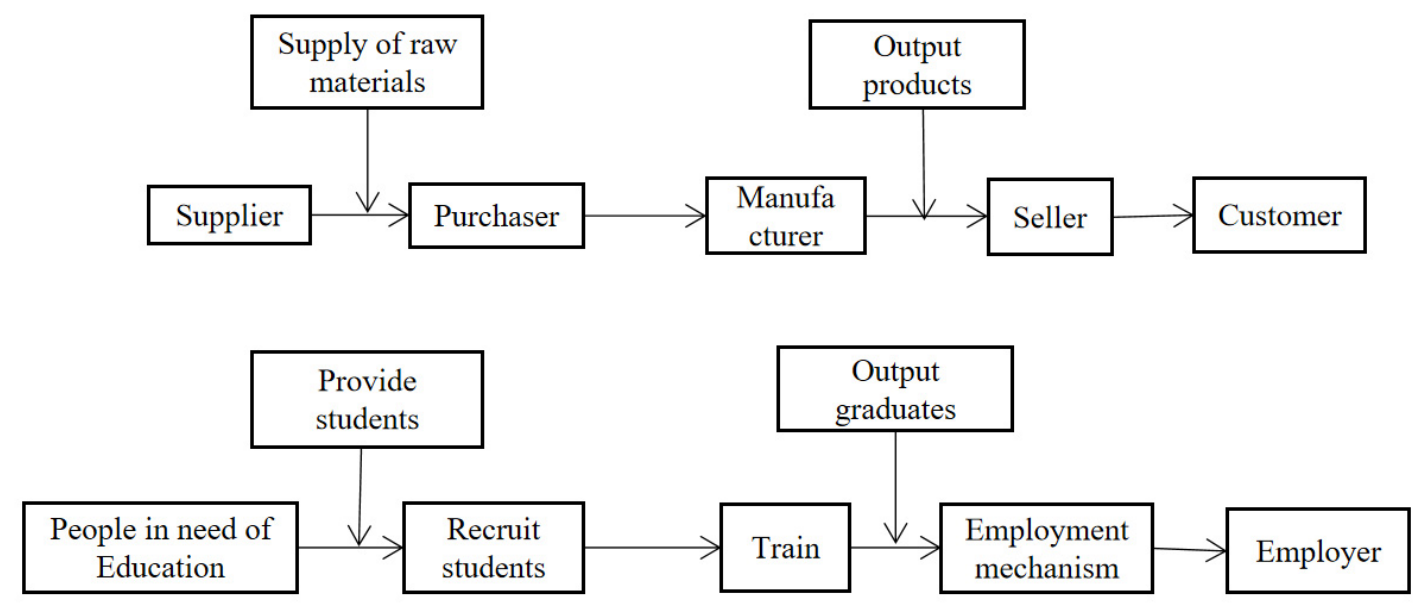

Figure 1. The commonness of supply chain in higher education and general enterprises

The school should play a game of chess for the whole school, fully consider the functional layout and safety risk characteristics of each laboratory, and implement the classified and hierarchical management system of laboratory safety work. Therefore, in the experimental design, students can be effectively guided to participate in a certain process of experimental preparation and configuration. 


\subsection{Improve Students' Interest in Learning and Stimulate Their Innovative Ability}

Usually, students' classroom study is mostly theoretical study, but in the laboratory, students can combine their theoretical knowledge with applied skills, and get certain results through experimental inspection. Colleges and universities should play a game of chess, fully consider the functional layout and safety risk characteristics of each laboratory, and implement the classified management system of laboratory safety work. Teachers can make full use of the supply chain management laboratory to understand and learn the latest technology, and provide services for the establishment, application and research of their projects. At the same time, we can also use the laboratory to simulate all links of the enterprise supply chain, collect relevant theoretical data, and then verify our own research conclusions. If the results achieve the expected effect, students will have a strong sense of achievement. If they fail to achieve the expected effect, they will also arouse students' competitive heart and thirst for knowledge, which is conducive to improving students' interest in autonomous learning, and let students grasp the knowledge more firmly. Laboratory construction is one of the main contents of practice links in Colleges and universities. Laboratory construction includes equipment procurement, maintenance, renewal and other aspects. At present, the procurement of laboratory equipment in Colleges and universities follows the provisions of the "Bidding Law $>>$ and is uniformly managed by the functional departments of colleges and universities, as shown in Figure 2.

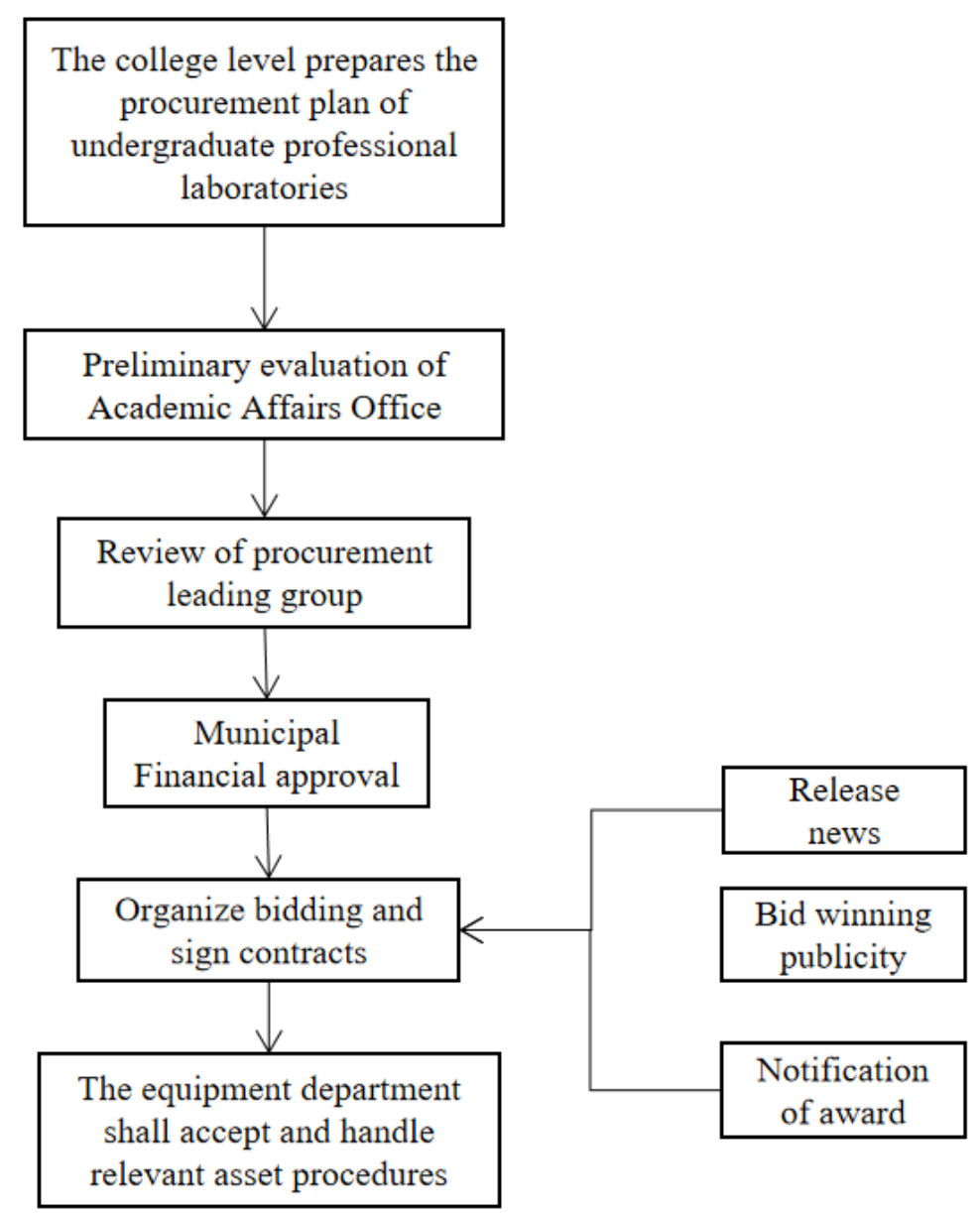

Figure 2. The procurement of laboratory equipment in colleges

Conduct training for all employees to improve safety awareness. Fully understand the importance of drug quality and service quality, and strengthen the safety awareness of "responsibility is more important than Mount Tai". Students can use the laboratory to design projects and carry out research on some projects, cultivate innovative consciousness through experimental inspection, and use the 
existing resources of the laboratory to develop and design the supply chain management information system. Students can not only rely on the laboratory for project design, subject application and project approval, but also use the laboratory to complete the experimental research of relevant projects and analyze the experimental data and experimental process.

\section{Application of Supply Chain Management Laboratory in Teaching and Research in Colleges and Universities}

\subsection{Application in Teaching}

This is the most common way at present, that is, to properly increase students' experimental study outside the normal teaching, so that students can test what they have learned in class through experiments and deepen their understanding and mastery of what they have learned. In the supply chain of higher education, the enrollment scale and specialty setting (i.e., output and product structure) of pharmaceutical students are estimated in advance by Jiangsu Education Department and Nanjing University of Traditional Chinese Medicine before students enter the production process. The formulation of laboratory safety management system must be routine, and the most common work should be institutionalized and standardized to ensure the effectiveness of the system. For some practical courses, we can make full use of ERP software, Guanglianda software, CAD software, UFIDA software, etc. in the laboratory to carry out teaching, and find ways to help students better master the systems used in future work, so that students can adapt to work better and faster in the future. Pharmaceutical employers passively accept pharmaceutical college students trained by conforming to supply chain education. Compared with the traditional equipment procurement, the relationship between material supply and demand has not changed. However, due to the strategic cooperation and the establishment of role partnership among enterprises in the supply chain, the concept and operation of procurement have changed greatly. As shown in Table 1.

Table 1. The concept and operation of procurement have changed greatly

\begin{tabular}{|c|c|c|}
\hline Characteristic & Traditional purchasing mode & Supply chain management procurement mode \\
\hline Focal point & $\begin{array}{c}\text { Under the condition of qualified quality, } \\
\text { choose the supplier with the lowest price } \\
\text { through multi-supplier competition }\end{array}$ & $\begin{array}{c}\text { On the basis of information sharing, coordinate } \\
\text { the implementation of various plans, realize } \\
\text { user-oriented job management, and simplify } \\
\text { the procurement process }\end{array}$ \\
\hline $\begin{array}{c}\text { Consideration } \\
\text { factor }\end{array}$ & $\begin{array}{c}\text { Price, quality, delivery time and price } \\
\text { are preferred }\end{array}$ & $\begin{array}{c}\text { Price is not the main factor. Quality is the most } \\
\text { important. Including product quality, delivery } \\
\text { quality, service and other aspects }\end{array}$ \\
\hline Means of control & $\begin{array}{c}\text { After-the-fact control, passing standards } \\
\text { and standardizing inspection }\end{array}$ & $\begin{array}{c}\text { Provide information anti-debt and education } \\
\text { support and training support, and promote } \\
\text { quality improvement and fulfill the promise of } \\
\text { quality children through node management of } \\
\text { supply chain }\end{array}$ \\
\hline $\begin{array}{c}\text { Transaction } \\
\text { process }\end{array}$ & $\begin{array}{c}\text { Short-term cooperation between } \\
\text { universities and suppliers. Long-term } \\
\text { procurement, repeated bidding and } \\
\text { negotiation, high procurement and } \\
\text { transaction costs }\end{array}$ & $\begin{array}{c}\text { Less suppliers, or even a single supplier or } \\
\text { integrator. Do not need to quote many times } \\
\text { and reduce transaction costs }\end{array}$ \\
\hline Batch & $\begin{array}{c}\text { Batch ordering within a certain period of } \\
\text { time }\end{array}$ & $\begin{array}{c}\text { Small batch or even single order } \\
\text { Information } \\
\text { communication }\end{array}$ \\
$\begin{array}{c}\text { Is the bidding game, universities and } \\
\text { suppliers, suppliers and suppliers have } \\
\text { asymmetric information, slow response } \\
\text { ability and lack the ability to cope with } \\
\text { changes in demand }\end{array}$ & $\begin{array}{c}\text { Supplier demand information is shared in the } \\
\text { supply chain, and manufacturing, procurement } \\
\text { and service are operated synchronously, which } \\
\text { improves the response ability to changes in } \\
\text { end-user demand }\end{array}$ \\
\hline
\end{tabular}


Despite the large number of graduates, they cannot fully meet the needs of employers in the pharmaceutical industry, resulting in a contradiction between supply and demand. Fully relying on the laboratory, actively carry out college students' innovation and entrepreneurship competitions and science and technology competitions, such as enterprise simulation operation competition, simulation securities investment competition, accounting competition and engineering drawing competition, to cultivate and stimulate students' innovation consciousness and innovation ability. Regularly carry out the safety risk assessment of laboratory teaching and scientific research activities, establish scientific experimental operation procedures and comprehensive safety plans, establish a full-cycle management system of hazard sources, establish safety risk distribution files and databases of major hazard sources, and formulate classification management and disposal schemes of hazard sources.

\subsection{Application in Scientific Research}

Only by giving full play to the platform role of supply chain management laboratory in scientific research and constantly stimulating and improving the enthusiasm of teachers and students to love scientific research and actively carry out scientific research, can we promote the stable, healthy and sustainable development of the laboratory. Colleges and universities gradually carry out enrollment consultation for senior high school students, career planning guidance for post enrollment students, employment guidance and interview skills training for graduating students, etc. However, it is difficult to fundamentally solve the employment problem only based on students if we do not strengthen the flexible overall coordination and cooperation among the main bodies of the supply chain. The formulation of laboratory safety management system must be routine, and the most common work should be institutionalized and standardized to ensure the effectiveness of the system. One of the main objectives of the construction of supply chain management laboratory is to provide a scientific research platform for teachers and serve teachers' scientific research. According to the operation difficulty of different laboratory instruments and equipment, combined with the actual situation of users, fully consider the enforceability of the guarantee system, and formulate targeted safety behavior norms. As the "core enterprise" of the supply chain, colleges and universities play an important role in the overall optimization of the supply chain, and play a huge role. Students can be encouraged to actively participate in scientific research and innovation by actively carrying out various scientific research, science and technology competitions and allocating special funds. This can not only train students' ability of scientific research and innovation, but also fully improve the utilization rate of laboratories.

\section{Conclusion}

In a word, the purpose of establishing supply chain management laboratory in Colleges and universities is to provide services for teachers and students. The safety management of university laboratory is a basic work that requires full participation, long-term persistence and unremitting efforts. Whether the cultivated products (i.e., pharmaceutical college students) can be favored by employers in the pharmaceutical industry, to achieve successful employment, and then realize personal value and the income of long-term investment in family education is one of the important criteria to judge the success of pharmaceutical higher education. Pharmaceutical care is not a simple service project, but a service system with rich content, high degree of specialization and high public expectation. People, things and environment are involved. With the implementation of all-round open management of laboratories, the scope of safety precautions involved is wider and more complex, and safety management will face greater challenges. The planning and construction of supply chain management laboratories in colleges and universities should closely focus on the laboratory's own construction goals, and fully meet the needs of teachers and students for teaching and scientific research. Through drug supply chain management, we ensure the safety, effectiveness and economy of drugs, realize the value sharing and win-win of pharmaceutical companies, hospitals and patients, and provide a guarantee for the whole process of pharmaceutical service. 


\section{References}

[1] Li Yande, Li Feng, Chen Ping. The construction and application of supply chain management laboratory in colleges and universities[J]. University Education, 2019, 000(002):196-198.

[2] Bu Xianglei, Ye Hua, Xie Weihua. Analysis and Thinking on the Problems Existing in the Supply Chain Management of Medical Consumables[J]. Medical and Medical Equipment, 2018(9):82-85.

[3] Ai Tingting. A new model of open laboratory supply chain management under the concept of industryuniversity-research cooperation[J]. Modern Scientific Instruments, 2019, 000(004):132-135.

[4] Zhang Chao, Lin Mingjian, Pan Mushan. Pay attention to the new version of GSP to ensure drug safety[J]. Strait Pharmacy, 2018, 30(09):284-286.

[5] Cai Yuting, Liu Yi. Design and construction of information management and information system for pharmacy laboratories in medical colleges and universities[J]. Software, 2019, 040(010):159-161.

[6] Xie Zhixin, Lin Shuisen, Zhou Yaming. Discussion on the safety management of chemical reagents in pharmacy laboratories of higher vocational colleges[J]. Continuing Medical Education, 2018, v.32 (08) :60-61.

[7] Zhang Hao, Xiong Dongyan, Sun Jian. Discussion on the safety management of chemical reagents in pharmacy laboratories of higher vocational colleges[J]. Breeding and Feed, 2019, 000(007): 116-118.

[8] Lai Rong, Chen Liuping, Zheng Saili, et al. Exploration and practice of using WeChat public platform to strengthen the management of basic chemistry laboratories[J]. University Chemistry, 2017, 32(003): 4348.

[9] Chang Di, Xu Tingting, Liu Zhuo, et al. Discussion on the micromanagement of the construction of the State Key Laboratory of Pharmacy[J]. Brand and Standardization, 2020, No.360(01):36-39.

[10] Lai Xinxin, Wang Hengjie. Discussion and analysis and countermeasures on the safety management of pharmacy laboratories in applied technology universities[J]. Journal of Science \& Technology Economics, 2020, v.28; No.711(13):123-124. 